\title{
DIFUSI INOVASI KESEHATAN MASYARAKAT MELALUI PROGRAM JAMBAN ARUM (ANTAR KE RUMAH) DI KECAMATAN SIMPANGKATIS KABUPATEN BANGKA TENGAH
}

\author{
Debi Devia $^{1}$ dan Siti Aisyah ${ }^{2}$
}

\author{
${ }^{1}$ Universitas Terbuka, Indonesia \\ 2Universitas Terbuka, Indonesia \\ 1debidjamhuri@gmail.com \\ ªisyah@ecampus.ut.ac.id \\ Submitted: 5 Juli 2020 \\ Revised: 13 Agustus 2020 \\ Accepted: 12 November 2020
}

\begin{abstract}
This study described the diffusion of public health innovation through the Arum Latrine Program (delivery to houses) in Simpangkatis District, Central Bangka Regency, which was carried out as an effort to improve performance through community services and development, especially in the community health development. The Arum Latrine Program was a program implemented from, by and for the Simpangkatis District with funding sourced from voluntary self-subsistent, so that currently the Arum Latrine Program was being proposed as one of the regional innovations.

The research method used a qualitative approach with descriptive methods. Data collection was conducted through interviews and observations. The interview was conducted to the informants who were selected using purposive sampling technique (the head of Simpangkatis District and sub-district employees, the head of village and village office staff, the Sector Police Chief, and the head of Simpangkatis health center) and snowball sampling technique (the community leaders and community recipients of Arum Latrine Program in the Simpangkatis District area). The data were analyzed using the theory of Everett M. Rogers (1964).

The conclusions were: 1) The diffusion innovations of public health through the Arum Latrine Program (Delivery to Houses) in Simpangkatis District had not been going well and had not been widely adopted. 2) The most powerful aspect in the diffusion of Arum Latrine innovation was the social system. 3) The obstacles in the diffusion of Arum Latrine innovation were the culture of open defecation among the community, the lack of initiative from other agencies to adopt the Arum Latrine Program, and misunderstandings of the apparatus in accepting the socialization of the Arum Latrine Program, especially regarding to the collection of voluntary donations. 4) The factor that supported the program was the social system existing in the community. It was because Simpangkatis District was still thick with its customs and culture, so that this social system became the most effective communication network in the diffusion of Arum Latrine innovation.
\end{abstract}

Keywords: Diffusion of Public Health Innovations, Arum Latrine Program

\section{PENDAHULUAN}

Undang-Undang Dasar 1945 Pasal 28 H menjelaskan bahwa "Setiap orang berhak hidup sejahtera lahir dan batin, bertempat tinggal dan mendapatkan lingkungan hidup yang baik dan sehat serta berhak memperoleh pelayanan kesehatan".
Dalam hal ini, Pasal 1 Ayat (1) Undang-Undang Nomor 36 Tahun 2009 tentang Kesehatan mengatakan kesehatan itu sendiri berarti "Keadaan sehat, baik secara fisik, mental, spiritual maupun sosial yang memungkinkan setiap orang untuk hidup produktif secara sosial dan ekonomis". Dengan begitu dapat 
diketahui bahwa kesehatan merupakan hak dan hal yang sangat penting bagi semua manusia, karena tanpa kesehatan yang baik tentu saja setiap manusia sulit dalam melaksanakan aktivitasnya sehari-hari.

Dengan berpedoman pada undang-undang Dasar 1945 seperti yang dijelaskan, tentunya menjadi tugas penting bagi Pemerintah Indonesia dalam membangun kesehatan setiap penduduknya. Hal ini pun tertuang didalam Bab III Keputusan Menteri Kesehatan RI Nomor HK.02.02/Menkes/52/2015 tentang Rencana Strategis Kementerian Kesehatan 2015-2019 yang mana didalamnya berisi tentang Tujuan Pembangunan Indonesia Sehat 2015-2019, yaknimeningkatkankesadaran, kemauan,kemampuan hidup sehat bagi setiap orang agar peningkatan derajat kesehatan masyarakat yang setinggi-tingginya dapat terwujud, melalui terciptanya masyarakat, bangsa dan negara Indonesia yang ditandai oleh penduduknya yang hidup dengan perilaku dan dalam lingkungan sehat, memiliki kemampuan untuk menjangkau pelayanan kesehatan yang bermutu, secara adil dan merata, serta memiliki derajat kesehatan yang setinggitingginya di seluruh wilayah Republik Indonesia.

Untuk mencapai Tujuan Pembangunan Kesehatan Indonesia ini, Pemerintah Indonesia juga telah melakukan berbagai upaya. Salah satu kebijakannya dalam Bab II Pasal 3 Ayat (2) Peraturan Menteri Kesehatan RI Nomor 03 Tahun 2014 tentang Sanitasi Total Berbasis Masyarakat adalah dengan melalui Program Stop Buang Air Besar Sembarangan sebagai salah satu pilar dari Sanitasi Total Berbasis Masyarakat. Stop Buang Air Besar Sembarangan adalah kondisi ketika setiap individu dalam suatu komunitas tidak lagi melakukan perilaku buang air besar sembarangan yang berpotensi menyebarkan penyakit.

Sama halnya dengan Kecamatan Simpangkatis di Kabupaten Bangka Tengah. Dalam dua tahun terakhir, yakni dimulai tahun 2016, untuk mendukung mencapai Tujuan Pembangunan Kesehatan Indonesia ini, Kecamatan Simpangkatis berinisiatif membuat Program Jamban Arum (Antar ke Rumah). Program ini dimana Kecamatan Simpangkatis bekerja sama dengan instansi yang ada di wilayah Kecamatan Simpangkatis termasuk masyarakat didalamnya untuk membuatkan jamban gratis dengan dana bersumber dari swadaya sukarela.

Menariknya, inovasi Kecamatan Simpangkatis melalui Program Jamban Arum saat ini sedang diusulkan sebagai salah satu inovasi daerah. Oleh karenanya, inovasi tersebut harus disebarluaskan yang sebagaimana prosesnya kita sebut sebagai difusi inovasi.

HarusnyainovasiJamban Arumini didifusikan di wilayah Kecamatan Simpangkatis dikarenakan masih banyaknya desa di Kecamatan Simpangkatis yang belum Deklarasi menjadi Desa ODF/ SBS. Dari 10 desa yang ada di wilayah Kecamatan Simpangkatis, baru 3 desa yang sudah deklarasi menjadi Desa ODF/ SBS (Open Defecation Free/ Stob Buang Air Besar Sembarangan), sedangkan sisanya yakni sebanyak 7 desa lainnya belum deklarasi.

Selain itu, setelah 2 tahun program ini berjalan, pada kenyataannya masih banyak masyarakat di wilayah Kecamatan Simpangkatis yang belum memiliki jamban dirumahnya. Dengan masih banyaknya penduduk yang belum memiliki jamban, tentunya dapat diketahui bahwa masyarakat Kecamatan Simpangkatis masih buang air besar secara sembarangan sehingga juga menyebabkan belum bersihnya lingkungan kesehatan yang ada di wilayah Kecamatan Simpangkatis itu sendiri. Hal ini pada akhirnya berdampak pada kesehatan masyarakat yang salah satunya yaitu menyebabkan penyakit berbasis lingkungan. Dari data yang diperoleh tahun 2017 lalu dari Dinas Kesehatan Kabupaten Bangka Tengah, ada 1.095 kasus penyakit berbasis lingkungan yang terjadi di Kecamatan Simpangkatis seperti diare dan berbagai jenis penyakit kulit.

Disisi lain, dengan melihat kondisi masyarakat yang ada, belum adanya pengadopsian inovasi program Jamban Arum dari pemerintah, baik ditingkat pemerintahan desa di wilayah Kecamatan Simpangkatis itu sendiri, maupun pemerintahan Kecamatan lain yang ada di Kabupaten Bangka Tengah secara keseluruhan.

\section{TINJAUAN PUSTAKA}

Yogi Suwarno (2016:12) mengungkapkan bahwa Inovasi adalah kegiatan yang meliputi seluruh 
proses menciptakan dan menawarkan jasa atau barang baik yang sifatnya baru, lebih baik atau lebih murah dibandingkan dengan yang tersedia sebelumnya. Udin Syaifudin Sa'ud (2014:4) juga mengutip pengertian lain dari inovasi menurut para ahli yaitu:

1. Sebuah inovasi adalah sebuah ide dan sebuah cara/langkah baru untuk untuk melengkapi kesadaran sosial (Donal P. Ely).

2. Inovasi adalah ide, tindakan ataupun sesuatu yang sudah ada tetapi diperbaharui oleh sekelompok orang yang mengadopsinya. Inovasi adalah perubahan (Zaltman Duncan).

3. Inovasi adalah pilihan kreatif, pengaturan dan seperangkat manusia dan sumber - sumber material baru atau menggunakan cara unik yang akan menghasilkan peningkatan pencapaian tujuan - tujuan yang diharapkan (Huberman).

4. Sebuah inovasi adalah sebuah gagasan, metode, tindakan, produk, dan atau jasa yang dianggap baru oleh individu ataupun kelompok yang mengadopsinya. Anggapan sebagai ide terbaru oleh seseorang ditentukan oleh reaksinya dalam bertindak. Jika ide tersebut dianggap baru oleh orang tersebut, makaitu dikatakan sebuah inovasi. Baru yang dimaksud adalah bersifat kualitatif. (M. Rogers).

5. Inovasi adalah mengkreasikan dan mengimplementasikan sesuatu menjadi satu kombinasi. Dengan inovasi maka seseorang dapat menambahkan nilai dari produk, pelayanan, proses kerja, pemasaran,sistem pengiriman, dan kebijakan, tidak hanya bagi perusahaan tapi juga stakeholder dan masyarakat (Schumpeter).

Dengan merujuk pada pengertian-pengertian inovasi yang telah dijelaskan, inovasi mempunyai satu sifat dasar yaitu sifat kebaruan. Sifat kebaruan inilah yang menggantikan pengetahuan, cara, teknologi, objek atau penemuan yang lama yang sudah tidak efektif dalam menyelesaikan suatu masalah yang ada.

Inovasi yang telah dicetuskan perlu untuk disebarluaskan/ dikomunikasikan. Ahmed H. Tolba dan Maha Mourad menjelaskan dalam penyebaran inovasi dapat dilakukan secara difusi dan atau diseminasi. Difusi inovasi adalah adalah proses untuk mengkomunikasikan inovasi melalui sarana komunikasi pada kurun waktu tertentu dalam sistem sosial. Itu artinya bahwa difusi merupakan proses mengkomunikasikan sebuah ide atau gagasan dan/ atau metode yang dianggap baru dengan tujuan untuk melakukan pembaharuan.

Berdasarkan judul penelitian ini yaitu inovasi jamban arum (antar ke rumah), maka dipilih teori difusi inovasi model Everett M. Rogers (1983). Udin Syaefudin Sa'ud (20014:29) mengungkapkan bahwa Rogers menyatakan dalam proses difusi inovasi terdapat 4 (empat) elemen pokok, yaitu: suatu inovasi, dikomunikasikan melalui saluran komunikasi tertentu, dalam jangka waktu dan terjadi diantara anggotaanggota suatu sistem sosial.

1. Inovasi (gagasan, tindakan atau barang) yang dianggap baru oleh seseorang. Dalam hal ini, kebaruan inovasi diukur secara subjektif menurut pandangan individu yang menerimanya.

2. Saluran komunikasi, adalah alat untuk menyampaikan pesan-pesan inovasi dari sumber kepada orang lain/penerima. Saluran komunikasi yang digunakan disesuaikan dengan kuantitas penerima. Jika komunikasi dimaksudkan untuk memperkenalkan suatu inovasi kepada khalayak umumdantersebarluas, makasalurankomunikasi yang lebih tepat, cepat dan efisien, adalah media massa. Tetapi jika komunikasi untuk penerima secara personal, maka saluran komunikasi yang paling tepat adalah saluran interpersonal.

3. Jangka waktu, yakni proses keputusan inovasi dari mulai seseorang mengetahui sampai memutuskan untuk menerima atau menolaknya inovasi yang ada. Pengukuhan terhadap keputusan itu sangat berkaitan dengan dimensi waktu. Paling tidak dimensi waktu terlihat dalam (a) proses pengambilan keputusan inovasi, (b) keinovatifan seseorang (relatif lebih awal atau lebih lambat dalam menerima inovasi), dan (c) kecepatan pengadopsian inovasi dalam sistem sosial.

4. Sistem sosial (warga masyarakat) merupakan kumpulan unit yang berbeda secara fungsional dan terikat dalam kerjasama untuk memecahkan masalah dalam rangka mencapai tujuan bersama. Anggota sistem sosial dapat individu, kelompok 
informal, organisasi dan sub sistem yang lain.

\section{Kesehatan Masyarakat}

Eliana dan Sri Sumiati (2016:3) mengatakan bahwa Kesehatan Masyarakat adalah ilmu dan seni memelihara, melindungi dan meningkatkan kesehatan masyarakat melalui usaha-usaha pengorganisasian masyarakat (Ikatan Dokter Amerika, AMA, 1948). Kesehatan masyarakat diartikan sebagai aplikasi dan kegiatan terpadu antara sanitasi dan pengobatan dalam mencegah penyakit yang melanda penduduk atau masyarakat. Kesehatan masyarakat adalah kombinasi antara teori (ilmu) dan Praktek (seni) yang bertujuan untuk mencegah penyakit, memperpanjang hidup, dan meningkatkan kesehatan penduduk (masyarakat). Kesehatan masyarakat adalah sebagai aplikasi keterpaduan antara ilmu kedokteran, sanitasi, dan ilmu dalam mencegah penyakit yang terjadi di masyarakat.

Tujuan Kesehatan masyarakat baik dalam bidang promotif, preventif, kuratif dan adalah tiap warga masyarakat dapat mencapai derajat kesehatan yang setingitinggi baik fisik, mental, serta diharapkan berumur panjang.

\section{Jamban Arum (Antar ke Rumah)}

Jamban Arum (Antar ke Rumah) merupakan salah satu inovasi kebijakan dari Pemerintah Kecamatan Simpangkatis Kabupaten Bangka Tengah untuk mewujudkan masyarakatnya yang hidup dengan perilaku dan dalam lingkungan sehat. Kebijakan ini merupakan pembuatan satu jamban satu rumah dengan menggunakan anggaran sukarela dari seluruh aparatur yang ada diwilayah Kecamatan Simpangkatis, antara lain pegawai kecamatan, pegawai Puskesmas, pegawai KUA, Polsek, perangkat desa dan lain-lain. Pembuatanjamban ini dilakukan secara gotong royong oleh masyarakat setempat dan secara keseluruhan dilakukan secara terpadu antara partisipasi masyarakat dan aparatur yang ada diwilayah Kecamatan Simpangkatis.

\section{METODE PENELITIAN}

Metode penelitian menggunakan pendekatan kualitatif metode deskriptif-induktif. Instrumen penelitian yang digunakan melalui wawancara dan observasi.
Informan dipilih dengan menggunakan teknik campuran yakni teknik purposive sampling dan teknik. bola salju (snowball sampling). Adapun informan yang menggunakan teknik purposive sampling yaitu :

1. Camat Simpangkatis;

2. Pegawai Kecamatan Simpangkatis;

3. Kepala dan Perangkat Desa di wilayah Kecamatan Simpangkatis;

4. Kapolsek Simpangkatis;

5. Kepala Puskesmas Kecamatan Simpangkatis;

Sedangkan informan yang menggunakan teknik snowball sampling yaitu :

1. Tokoh masyarakat di wilayah Kecamatan Simpangkatis, serta

2. Masyarakat penerima Jamban Arum diwilayah Kecamatan Simpangkatis.

\section{HASIL}

\section{DIFUSI INOVASI JAMBAN ARUM}

Seperti yang telah dijelaskan pada bab sebelumnya, Udin Syaefudin Sa'ud (20014:29) mengungkapkan bahwa Rogers menyatakan "Dalam proses difusi inovasi terdapat 4 (empat) elemen pokok, yaitu: suatu inovasi, dikomunikasikan melalui saluran komunikasi tertentu, dalam jangka waktu dan terjadi diantara anggota-anggota suatu sistem sosial.

\section{Inovasi}

Berdasarkan hasil wawancara yang dilakukan dengan Camat dan Kasi Pembangunan Kecamatan Simpangkatis serta para penerima Jamban Arum, Program Jamban Arum di Kecamatan Simpangkatis Kabupaten Bangka Tengah adalah yang pertama kali dilakukan dan sangat memberi manfaat bagi masyarakat. Selain itu juga, dalam mendapatkannya tidak sulit dan sudah dapat dilihat serta dicoba.

Dengan demikian, dapat dianalisa bahwa indikator inovasi yang ditinjau dari lima atribut yang menandaisuatugagasanatau carabaru, dapat diketahui bahwa elemen inovasi berupa tingkat penerimaan masyarakat terhadap kebaruan inovasi dari difusi inovasikesehatanmasyarakatmelalui ProgramJamban Arum (Antar ke Rumah) di Kecamatan Simpangkatis 
Kabupaten Bangka Tengah dapat dikatakan sudah baik. Ini ditunjukkan dengan bermanfaatnya Program Jamban Arum yang dilakukan, sudah dilakukan sesuai dengan kondisi masyarakat yang ada, program dilakukan dengan mudah, serta program jamban arum ini sudah dilaksanakan dan digunakan. Jadi inovasi Program Jamban Arum tersebut dapat dikatakan sebagai inovasi baru dan sudah diterima dengan baik. 2. Saluran Komunikasi

Selain inovasi, persyaratan kedua bagi keberhasilan difusi inovasi menurut Everett M. Rogers (1964) adalah faktor saluran komunikasi.

Berdasarkan hasil wawancara yang dilakukan, dapat diketahui bahwa saluran komunikasi yang digunakan oleh pihak Kecamatan Simpangkatis dalam difusi inovasi kesehatan masyarakat melalui Program Jamban Arum (Antar ke Rumah) di Kecamatan Simpangkatis Kabupaten Bangka Tengah sudah efektif melalui komunikasi media massa berupa sosialisasi dan komunikasi interpersonal berupa koordinasi langsung baik dengan pihak terkait maupun kepada penerima jamban.

\section{Jangka Waktu}

Berdasarkan hasil wawancara yang dilakukan dengan camat, kepala seksi dan staf seksi pembangunan Kecamatan Simpangkatis, staf Desa Celuak dan Desa Beruas serta penerima jamban, dapat disimpulkan bahwa jangka waktu yang dibutuhkan dalam difusi inovasi kesehatan masyarakat melalui programjamban arum (antar ke rumah) di Kecamatan Simpangkatis Kabupaten Bangka Tengah dapat dikatakan sangat lama.

\section{Sistem Sosial}

Melihat hasil dari wawancara yang dilakukan, jadi dapat disimpulkan bahwa difusi inovasi kesehatan masyarakat melalui Program Jamban Arum (Antar ke Rumah) di Kecamatan Simpangkatis Kabupaten Bangka Tengah terjadi didalam sistem sosial yang ada dimasyarakat.

Setelah melihat hasil dari pembahasan yang telah diuraikan, dapat disimpulkan bahwa difusi inovasi kesehatan masyarakat melalui Program Jamban Arum (Antar ke Rumah) di Kecamatan Simpangkatis Kabupaten Bangka Tengah belum berjalan dengan baik. Hal ini dikarenakan program
Jamban Arum hanya dikomunikasikan dan diterima saja didalam masyarakat tetapi tidak terjadinya proses adopsi dari program tersebut. Hal ini ditunjukkan dari keempat faktor yang dicetuskan oleh Rogers (1964) bahwasanya difusi inovasi terdiri dari empat elemen yakni inovasi, saluran komunikasi, jangka waktu dan sistem sosial. Untuk difusi inovasi kesehatan masyarakat melalui Program Jamban Arum (Antar ke Rumah) di Kecamatan Simpangkatis Kabupaten Bangka Tengah itu sendiri, dapat diketahui bahwa inovasi yang dicetuskan merupakan inovasi baru yang tersebar melalui saluran komunikasi yang efektif yakni menggunakan saluran komunikasi media dan komunikasi interpersonal, serta terjadi didalam sistem sosial yang berlaku di Kecamatan Simpangkatis. Namun dari segijangka waktunya berjalan sangat lama hal ini dibuktikan dengan belum adanya pengadopsian terhadap program Jamban Arum hingga saat ini. Selain itu, dengan menganalisa hasil dari pembahasan yang dilakukan, dapat disimpulkan juga bahwa aspek yang paling kuat dalam difusi inovasi Jamban Arum adalah sistem sosial. Karena melalui sistem sosial ini difusi inovasi Jamban Arum terjadi dengan sangat cepat.

Dengan belum berjalan baiknya difusi inovasi Program Jamban Arum dikarenakan belum adanya pengadopsian sehingga jangka waktu difusinya berjalan sangat lama, oleh karena itu tentunya dapat dipastikan bahwa perlunya sebuah sikap dari seorang pelaksana dalam penerapan/ pengadopsian dari Program Jamban Arum tersebut.

Sikap pelaksana (disposisi) dalam hal ini berperan dalam menentukan/pun mengambil kebijakan untuk mengadopsi Program Jamban Arum. Edwards III (dalam Syafri dan Setyoko, 2008:48) menjelaskan bahwa Kecenderungan-kecenderungan merupakan praduga-praduga dari para pelaksana terhadap suatu kebijakan. Jika para pelaksana bersikap baik karena menerima suatu kebijakan, kemungkinan besar mereka akan melaksanakan kebijakan tersebut secara bersungguh-sungguh seperti yang diharapkan pembuat kebijaksanaan. Sebaliknya jika perspektif dan tingkah laku para pelaksana berbeda dengan para pembuat kebijakan, maka proses implementasi kebijakan akan mengalami kesulitan. 
Disposisi juga menyangkut persepsi, kewenangan, pemahaman dan komitmen para pelaksana (implementor) untuk menerapkan suatu kebijakan. Terdapat tiga kemungkinan sikap dari disposisi yaitu menerima, menolak atau bersikap netral.

Faktor Penghambat dan Faktor Pendukung dalam Difusi Inovasi Jamban Arum

Adapun hambatan yang ditemui di lapangan terhadap difusi inovasi kesehatan masyarakat melalui program jamban arum (antar ke rumah) di Kecamatan Simpangkatis Kabupaten Bangka Tengah yaitu :

1. Masih membudayanya $\mathrm{BAB}$ sembarangan dikalangan masyarakat. Hal ini menjadikan difusi inovasi Program Jamban Arum hanya sekedar diterima oleh masyarakat dan banyak pihak, namun tidak untuk diadopsi secara luas.

2. Kurangnya inisiatif baik dari pemerintah desa di wilayah Kecamatan Simpangkatis itu sendiri maupun instansi lain untuk mengadopsi Jamban Arum sehingga inovasi Jamban Arum hanya sekedar diterima dan disebarluaskan tetapi tidak untuk diterapkan.

3. Kesalahpahaman aparatur dalam menerima sosialisasi Program Jamban Arum. Masih adanya anggapan bahwa pemungutan dana sukarela untuk Program Jamban Arum sebagai pungli. Hal ini pada akhirnya berdampak pada sulitnya inovasi Jamban Arum didifusikan hingga diadopsikan.

Sedangkan untuk faktor pendukung yang ditemui di lapangan terhadap difusi inovasi kesehatan masyarakat melalui Program Jamban Arum (Antar ke Rumah) di Kecamatan Simpangkatis Kabupaten Bangka Tengah yaitu sistem sosial yang berlaku dikalangan masyarakat Simpangkatis. Sistem sosial ini menjadi jejaring komunikasi yang paling efektif dalam difusi atau penyebaran inovasi Jamban Arum.

\section{KESIMPULAN DAN SARAN}

\section{Kesimpulan}

Berdasarkan hasil analisis dan penelitian terhadap objek penelitian Difusi Inovasi Kesehatan Masyarakat Melalui Program Jamban Arum (Antar ke Rumah) di Kecamatan Simpangkatis Kabupaten
Bangka Tengah, maka penulis mengambil kesimpulan sebagai berikut:

1. Difusi inovasi kesehatan masyarakat melalui Program Jamban Arum (Antar ke Rumah) di Kecamatan Simpangkatis Kabupaten Bangka Tengah belum berjalan dengan baik.

2. Aspekyang paling kuat dalam difusi inovasi Jamban Arum adalah sistem sosial.

3. Hal-hal yang menjadi faktor penghambat difusi inovasi kesehatan masyarakat melalui program jamban arum (antar ke rumah) di Kecamatan Simpangkatis Kabupaten Bangka Tengah yaitu masih membudayanya BAB sembarangan dikalangan masyarakat, kurangnya inisiatif dari instansi lain untuk mengadopsi Jamban Arum serta kesalahpahaman aparatur dalam menerima sosialisasi Program Jamban Arum, khususnya terkait pemungutan sumbangan sukarela.

4. Sedangkan yang menjadi faktor pendukung difusi inovasi kesehatan masyarakat melalui Program Jamban Arum (Antar ke Rumah) di Kecamatan Simpangkatis Kabupaten Bangka Tengah adalah sistem sosial yang berlaku dimasyarakat.

\section{Saran}

Berdasarkan hambatan dan upaya yang dilakukan sebagaimana yang telah dipaparkan sebelumnya, diberikanbeberapasaranyang diharapkan dapat bermanfaatbagi Kecamatan Simpangkatis dalam Difusi Inovasi Kesehatan Masyarakat Melalui Program Jamban Arum (Antar ke Rumah), yaitu :

\section{Saran teoritis}

Hendaknya menambah elemen "Sikap Pelaksana" dalam Teori Difusi Inovasi sebagai pelengkap dari 4 elemen sebelumnya yakni inovasi, saluran komunikasi, jangka waktu dan sistem sosial. Yang mana "Sikap Pelaksana" ini, berdasarkan penelitian yang dilakukan dapat menjadi salah satu indikator yang dapat mempengaruhi keberhasilan dari sebuah proses difusi inovasi.

\section{Saran praktis}

a) Agar Kecamatan Simpangkatis bekerjasama dengan Puskesmas Simpangkatis untuk meningkatkan sosialisasi tentang bahayanya akibat dari $\mathrm{BAB}$ sembarangan terhadap kesehatan. 
b) Hendaknya Kecamatan Simpangkatis membentuk sem acam "Polisi Tinja" untuk mengurangi dan mengawasi warga yang BAB sembarangan.

c) Agar Kecamatan Simpangkatis membuat forum OPD Tingkat Kecamatan khusus dalam pelaksanaan Program Jamban Arum.

\section{DAFTAR PUSTAKA}

Aida Vitalaya S. Hubis, dkk. 2010. Komunikasi Inovasi ed 2. Jakarta: Universitas Terbuka.

Arikunto, Suharsimi. 2010. Prosedur Penelitian Suatu Pendekatan Praktik. Jakarta: PT. Rineka Cipta.

Atikah Proverawati, Eni Rahmawati. 2012. Perilaku hidup bersih dan sehat (PHBS). Yogyakarta: Nuha Medika.

Departemen Kesehatan RI, 2004. Kebijakan Dasar Kesehatan Masyarakat Tahun 2004. Penerbit Depkes RI. Jakarta.

Eliana, dan Sri Sumiati. 2016. Modul Bahan Ajar Cetak Kebidanan : Kesehatan Masyarakat. Jakarta Selatan: Pusdik SDM Kesehatan

Furchan, Ahmad. 2004. Pengantar Penelitian dalam Pendidikan. Yogyakarta: Pustaka Pelajar Offset

Harun, Rochajat, Elvinaro Ardianto. 2012. Komunikasi Pembangunan \& Perubahan Sosial: Perspektif Dominan, Kaji Ulang, dan Teori Kritis. Jakarta : Rajawali Pers.

J. Setiadi, Nugroho. 2003. Perilaku Konsumen Konsep dan Implikasi untuk Strategi dan Penelitian Pemasaran. Jakarta: Kencana.

Kountur, Ronny. 2003. Metode Penelitian Untuk Penulisan Skripsi dan Tesis. Jakarta: PPM

Moleong, Lexy J. 2014. Metode Penelitian Kualitatif. Bandung : Rosda.

Nazir, Moh. 2011. Metode Penelitian. Bogor : Ghalia Indonesia.

Notoatmodjo, Soekidjo. 2003. Ilmu Kesehatan Masyarakat : Prinsip-prinsip Dasar. Jakarta : PT. Rineka Cipta.

Rogers. M. Everett. 1971. Diffusion of Innovations: Third Edition. New York: The Free Press.

Sugiyono. 2012. Metode Penelitian Kuantitatif Kualitatif dan R \& D. Bandung : Alfabeta.
2014. Metode Penelitian Kombinasi (Mixed Methods). Bandung : Alfabeta

2016. Metode Penelitian Kuantitatif Kualitatif dan R \& D. Bandung : Alfabeta.

Suwartono. 2014. Dasar-Dasar Metodelogi Penelitian. Yogyakarta : CV. Andi Offset

Udin Syaefudin Sa'ud, 2014. Inovasi Pendidikan, Bandung: Alfabeta.

Syafri, Wirman dan Israwan Setyoko. 2008. Implementasi Kebijakan Publik dan Etika Profesi Pamong Praja. Sumedang : Alqaprint Jatinangor.

Yogi Suwarno, 2016. Inovasi di Sektor Publik. Jakarta: STIA-LAN.

\section{Jurnal-Jurnal}

Ahmed H. Tolba, Maha Mourad. Individual and Cultural Factor affecting Diffusion of Innovation, Journal International Business and Cultural Studies. Diakses dari www.aabri.com/ manuscripts/11806.pdf. \pada hari Minggu, 18 Februari 2018.

Fatonah, Siti, “Jurnal Difusi Inovasi Teknologi Tepat Guna Di Kalangan Wanita Di Desa Kasongan Yogyakarta”. Volume 6, Nomor 2 Mei-Agustus 2008.

Firmansyah, 2009. Memiliki dan menggunakan Jamban Sehat. Retrieved from http:// repository.usu.ac.id. diakses pada hari Senin, 12 Februari 2018.

Hajaroh, Mami, "Jurnal Difusi Kebijakan Pengarusutamaan Gender Pada Individu: Refleksi Terhadap Metode Penelitian Difusi”. Universitas Negeri Yogyakarta. Vol. Nomor 2 Tahun 2014.

Pratama, Wahyu Herawan, 2014, "Jurnal Difusi Inovasi Program Jaminan Kesehatan Nasional”. Jurnal Universitas Sebelas Maret Surakarta.

Rusmiati, Dewi Ariningrum, "Analisis Difusi Inovasi Dan Pengembangan Budaya Kerja Pada Organisasi Birokrasi”. Volume 6, Nomor 2 November 2015.

Sururi, Nazarus, dkk. 2013. Pelaksanaan 
Gerakan Membangun Msyarakat Sehat (GERBANGMAS SIAGA) Sebagai Inovasi dalam Pelayanan Kesehatan di Kelurahan Citrodiwangsan Kecamatan Lumajang Kabupaten Lumajan. Jurnal Administrasi Publik (JAP). Vol 1, No. 2:238-247. Diakses dari http://download.portalgaruda.org/article.php? article $=72880 \& v a l=4924 \&$ title $=$ INOVASI $\% 20$ PEMBERDAYAAN\%2OMASYARAKAT\%20 PERDESAAN\%2OSTUDI\%2OKASUS\%20 PADA\%2OUNIT\%2OPENGELOLA\% 20 KEGIATAN\%20(UPK)\%2ODALAM\%20 PELAKSANAAN\% 20 PROGRAM\% 20 NASIONAL\%2OPEMBERDAYAAN\%20 M A S Y A R A K A T - M A N D I R I \% 20 PERDESAAN\% 20(PNPMMPD)\% 20 KECAMATAN\%2OWONOSALAM\% 20 KABUPATEN\%2ODEMAK pada hari Jum'at, 21 September 2018.

Teguh Kurniawan, Daniel, dkk. 2013. Inovasi Pemberdayaan Masyarakat Perdesaan Studi Kasus pada Unit Pengelola Kegiatan (UPK) dalam Pelaksanaan Program MasyarakatMandiri Perdesaan (PNPM-MPD) Kecamatan Wonosalam Kabupaten Demak. Vol. 2 Nomor 2. Diakses dari http://id.portalgaruda.org/?ref= browse\&mod=viewarticle\&article $=72880$ pada hari Kamis, 13 September 2018.

Teori H.L Blum dalam Hapsari et. al, "Pengaruh
Lingkungan Sehat, dan Perilaku Hidup Sehat Terhadap Status Kesehatan". Pusat Penelitian dan Pengembangan Ekologi dan Status Kesehatan Jakarta .Vol. 37, 2009.

\section{Peraturan Perundang-Undangan}

Undang-Undang Dasar 1945.

Undang-Undang Nomor 36 Tahun 2009 tentang Kesehatan.

Peraturan Menteri Kesehatan RINomoro3Tahun2014 tentang Sanitasi Total Berbasis Masyarakat.

Keputusan Menteri Kesehatan RI Nomor 852 Tahun 2008 tentang Strategi Nasional Sanitasi Total Berbasis Masyarakat.

Keputusan Menteri Kesehatan RI Nomor HK.02.02/ Menkes/52/2015 tentang Rencana Strategis Kementerian Kesehatan 2015-2019.

\section{Lain-Lain}

Nurdien H. Kistanto dalam file://C:/Users/acer/ Downloads/13221-30842-1-SM.pdf (diakses pada hari Senin, 21 Mei 2019).

Profil Kecamatan Simpangkatis Tahun 2017.

Data Dinas Kesehatan Kabupaten Bangka Tengah Tahun 2016. 